\title{
RESEARCH
}

Open Access

\section{Dose-effect relationship and molecular mechanism by which BMSC-derived exosomes promote peripheral nerve regeneration after crush injury}

Jiuhong Zhao ${ }^{1,2 \dagger}$, Yali Ding ${ }^{3 \dagger}$, Rui He ${ }^{2,4 \dagger}$, Kui Huang ${ }^{1}$, Lu Liu', Chaona Jiang ${ }^{1}$, Zhuozhou Liu', Yuanlan Wang ${ }^{1}$, Xiaokai Yan ${ }^{1}$, Fuyang Cao ${ }^{1}$, Xueying Huang ${ }^{1}$, Yanan Peng ${ }^{1,2}$, Rui Ren ${ }^{1,2}$, Yuebin He ${ }^{1,2}$, Tianwei Cui ${ }^{1,2}$, Quanpeng Zhang ${ }^{1,2}$, Xianfang Zhang ${ }^{1,2}$, Qibing Li ${ }^{2}$, Yunqing Li ${ }^{2}$, Zhijian $\mathrm{Ma}^{1,2^{*}}$ and Xinan $\mathrm{Yi}^{1,2^{*}}$ (D)

\begin{abstract}
Background: The development of new treatment strategies to improve peripheral nerve repair after injury, especially those that accelerate axonal nerve regeneration, is very important. The aim of this study is to elucidate the molecular mechanisms of how bone marrow stromal cell (BMSC)-derived exosomes (EXOs) participate in peripheral nerve regeneration and whether the regenerative effect of EXOs is correlated with dose.

Method: BMSCs were transfected with or without an siRNA targeting Ago2 (SiAgo2). EXOs extracted from the BMSCs were administered to dorsal root ganglion (DRG) neurons in vitro. After $48 \mathrm{~h}$ of culture, the neurite length was measured. Moreover, EXOs at four different doses were injected into the gastrocnemius muscles of rats with sciatic nerve crush injury. The sciatic nerve functional index (SFI) and latency of thermal pain (LTP) of the hind leg sciatic nerve were measured before the operation and at 7, 14, 21, and 28 days after the operation. Then, the number and diameter of the regenerated fibers in the injured distal sciatic nerve were quantified. Seven genes associated with nerve regeneration were investigated by qRT-PCR in DRG neurons extracted from rats 7 days after the sciatic nerve crush.

Results: We showed that after $48 \mathrm{~h}$ of culture, the mean number of neurites and the length of cultured DRG neurons in the SiAgo2-BMSC-EXO and SiAgo2-BMSC groups were smaller than that in the untreated and siRNA control groups. The average number and diameter of regenerated axons, LTP, and SFI in the group with $0.9 \times 10^{10}$ particles $/ \mathrm{ml} \mathrm{EXOs}$ were better than those in other groups, while the group that received a minimum EXO dose $\left(0.4 \times 10^{10}\right.$ particles $\left./ \mathrm{ml}\right)$ was not significantly different from the PBS group. The expression of PMP22, VEGFA, NGFr, and S100b in DRGs from the EXO-treated group was significantly higher than that in the PBS control group. No significant difference was observed in the expression of HGF and Akt1 among the groups.

(Continued on next page)
\end{abstract}

\footnotetext{
*Correspondence: 147977092@qq.com; yixn001@163.com

†Jiuhong Zhao, Yali Ding and Rui He contributed equally to this work. ${ }^{1}$ Key Laboratory of Brain Science Research \& Transformation in Tropical Environment of Hainan Province, Hainan Medical University, Haikou, China Full list of author information is available at the end of the article
}

C C The Author(s). 2020 Open Access This article is licensed under a Creative Commons Attribution 4.0 International License, which permits use, sharing, adaptation, distribution and reproduction in any medium or format, as long as you give appropriate credit to the original author(s) and the source, provide a link to the Creative Commons licence, and indicate if changes were made. The images or other third party material in this article are included in the article's Creative Commons licence, unless indicated otherwise in a credit line to the material. If material is not included in the article's Creative Commons licence and your intended use is not permitted by statutory regulation or exceeds the permitted use, you will need to obtain permission directly from the copyright holder. To view a copy of this licence, visit http://creativecommons.org/licenses/by/4.0/ The Creative Commons Public Domain Dedication waiver (http://creativecommons.org/publicdomain/zero/1.0/) applies to the data made available in this article, unless otherwise stated in a credit line to the data. 
(Continued from previous page)

Conclusions: These results showed that BMSC-derived EXOs can promote the regeneration of peripheral nerves and that the mechanism may involve miRNA-mediated regulation of regeneration-related genes, such as VEGFA. Finally, a dose-effect relationship between EXO treatment and nerve regeneration was shown.

Keywords: Mesenchymal stem cells, Exosome, Neurons, Regeneration

\section{Background}

Clinical therapies for peripheral nerve injury still require improvement $[1,2]$. The development of new treatment strategies to improve peripheral nerve repair after injury, especially those that accelerate axonal nerve regeneration, is very important [1-4]. Moreover, the application of biotherapy to motor and dorsal root ganglion (DRG) neurons remains a major obstacle in the treatment of various neurological conditions, including peripheral nerve injury, motor neuron disease, and pain. Since the neuronal soma plays an important role in the initiation and control of axonal regeneration, targeted administration is an attractive strategy for peripheral nerve injury [5]. Selective regulation of sensory neuron gene expression has many applications in the peripheral nervous system. Subcutaneous peripheral injection of plasmid DNA combined with a nonviral cationic gelatin (CG) vector (CG/DNA) induced the expression of DRG genes in rat lumbar DRGs [6]. CG/DNA undergoes rapid retrograde transport through the sciatic and spinal nerves, and reporter mRNA expression in L4 and L5 DRGs can be detected within $60 \mathrm{~h} \mathrm{[6].} \mathrm{Mesenchymal}$ stem cells (MSCs) are self-proliferating multipotent stromal cells from the bone marrow, fat, dental pulp, umbilical cord blood, and other tissues [7-10]. It has been shown that BMSCs can promote regeneration [11-15], and on this basis, a paracrine-mediated mechanism has been established, and an increasing amount of evidence indicates that MSCs may provide a benefit due to their close proximity to damaged tissues through secretion of exosomes (EXOs), a type of extracellular vesicle (EV) [16-19]. The first data describing the ability of vesicles to function in intercellular communication were published in two very different papers in 1983. The term for these vesicles was coined by Johnstone et al. in 1989 [20, 21]. It is difficult to strictly classify all EVs, but until now, EVs were thought to mediate endocytosis when cells release multivesicular bodies $[18,19]$. EVs range in size from 30 to $150 \mathrm{~nm}$ [21]. Proteomic analysis of BMSC-derived EXO contents showed the presence of many factors in conditioned medium from BMSCs [22]. EXO mRNAs and microRNAs (miRNAs) (together with proteins), which are both functional, fuse with the cell membrane when delivered to another cell; this leads to the translation of new proteins [2]. The intracellular transfer of EXOs has now been demonstrated in many different types of cells, and EXOs from all these cell types have demonstrated the ability to use delivered miRNAs $[23,24]$. The characteristics of EXO uptake indicate that
EXOs from donor cells shuttle through intracellular vesicles to the endoplasmic reticulum and lysosome during transport [24]. BMSCs secrete EXOs that contain more than 150 different miRNA molecules that can be transferred to target cells [25]. Various studies have shown that EXOs play a major role in the therapeutic effects of BMSCs. BMSC EXOs from humans, rats, and mice exert therapeutic effects, which are mediated by EXO protein and RNA cargo, in various nervous system injury models $[14,15]$. More specifically, miRNAs carried by EXOs are involved in various key processes, such as nerve and vascular regeneration, and EXOs derived from Schwann cells, macrophages, and MSCs can promote peripheral nerve regeneration [24-27]. Vesna Bucan et al. [26] demonstrated that EXOs could promote the regeneration of injured nerves and improve motor functional recovery in regenerated nerves in a rat sciatic nerve crush (SNC) model. B Mead et al. [27] isolated EXOs from BMSCs and applied them to a rat optic nerve crush model, in which they promoted the survival of retinal ganglion cells (RGCs) and the regeneration of $\mathrm{RGC}$ axons while partially preventing RGC axonal loss and dysfunction. BMSC-derived EXOs demonstrated significant neuroprotective and neuritogenic effects when used to treat primary retinal cultures [27]. However, whether this effect on nerve regeneration is related to the concentration of EXOs has not yet been reported. In our previous study, we found that 5 days after EXOs were injected into the gastrocnemius muscle, significantly more EXOs in the DRG and spinal cord anterior horn were aggregated on the injection side than on the contralateral side, which indicates that EXOs undergo both retrograde axoplasmic transport and hematogenous transport (data not reported). Therefore, in this study, we injected different doses of EXOs into the gastrocnemius muscle in rats subjected to SNC to observe their nerve regenerative effects and preliminarily clarified the mechanism of this effect through molecular biological methods.

\section{Methods \\ Animals}

Fifty 6- to 8-week-old male and female Sprague-Dawley (SD) rats weighing 200-250 g (Changsha Tianqin Biotechnology, Changsha, Hunan, China) were housed in standard rat cages at a temperature of $21^{\circ} \mathrm{C}$ and a humidity of $55 \%$ under a $12 \mathrm{~h}$ light-dark cycle. The rats had unlimited access to water and food and were cared for by well-trained personnel. Animal sacrifice and tissue collection were performed according to the guidelines of 
the China Laboratory Animal Nursing and Use Regulations and with the approval of the Animal Ethics Committee of Hainan Medical University.

\section{BMSC culture and transfection with siRNA}

Primary BMSCs were harvested from the marrow of the femur and tibia of 2 SD rats, as previously described [27]. For cell culture, a total of $2 \times 10^{6}$ BMSCs were initially seeded into each T75 flask (Corning, Acton, MA) and cultured in medium that contained 89\% Minimum Essential Medium Eagle- $\alpha$-modification ( $\alpha$-MEM) (Gibco, 12561056, Gaithersburg, MD, USA), 10\% EXO-depleted FBS (Gibco, 10099141), and 1\% penicillin/streptomycin (HyClone, SV30010, Logan, UT, USA). The cells were maintained at $37{ }^{\circ} \mathrm{C}$ in $5 \% \mathrm{CO}_{2}$, and the cell culture medium was changed every $72 \mathrm{~h}$. Efforts were made to passage the cells when they reached $80 \%$ confluence; for this, $0.05 \%$ trypsin/EDTA (Thermo Fisher Scientific, 25300054, Grand Island, USA) was used. The passage 6 cells were analyzed by fluorescence-activated cell sorting (FACS) (ACEA, NovoCyte 1040 cytometer) using antibodies against both the CD45 (FITC-conjugated anti-rat CD45, eBioscience, 11-0461-80, Vienna, Austria) and CD44 (PE-conjugated anti-rat CD44, eBioscience, 120444-80) biomarkers [28]. To transfect the BMSCs with siRNA, Lipofectamine 3000 (Thermo Fisher, L3000008) was used according to the vendor's protocol. Briefly, passage 6 BMSCs grown to $70 \%$ confluence in $\alpha$-MEM were incubated with Lipofectamine 3000 reagent and an siRNA targeting Ago2 (SiAgo2) (Sino Biological, 3263, Peking, $\mathrm{PRC}$ ) or an interference control siRNA (SiScr) for $48 \mathrm{~h}$.

\section{Cell viability assay}

BMSCs were seeded on 96-well plates at a density of 5000 cells/well and incubated in serum-free medium for $72 \mathrm{~h}$. Then, the MTS Cell Proliferation Assay was applied and the plates were read by a spectrometer. The viability was determined by normalizing BMSCs cultured in serum-free medium to those cultured in 10\% FBS.

\section{EXO isolation}

Passage 6 BMSCs grown to $80 \%$ confluence (transfected with SiAgo2, transfected with SiScr or nontransfected) were washed 3 times with PBS and then incubated in serum-free medium for $72 \mathrm{~h}$, after which the cells were counted using a blood cell counter (approximately $2.5 \times$ $10^{7}$ cells). To isolate EXOs, a well-established protocol was followed with minor modifications [29]. Briefly, the supernatant from serum-free BMSC cultures was collected and centrifuged at $300 \times g$ for $10 \mathrm{~min}$ to remove any intact cells, which was followed by centrifugation at $2000 \times g$ for $20 \mathrm{~min}$ to remove dead cells and centrifugation at 10 , $000 \times g$ for $30 \mathrm{~min}$ to remove cell debris. The supernatant was filtered through a $0.2-\mu \mathrm{m}$ filter and then concentrated to approximately $9 \mu \mathrm{l}$ with an advanced centrifugal device (Pall, MAP100C36, Shanghai, PRC) with a MWCO of 100 $\mathrm{kDa}$. The retained sample containing EXOs was ultracentrifuged at $100,000 \times g$ for $70 \mathrm{~min}$ (Hitachi Optima TLX ultracentrifuge). All centrifugations were performed at $4{ }^{\circ} \mathrm{C}$. EXO pellets were resuspended in PBS and stored at $-80^{\circ} \mathrm{C}$ (Fig. 1a). EXO samples were analyzed using the Apogee A50 flow cytometry platform (A50-Micro, Apogee Flow Systems, UK).

\section{Western blotting}

To detect the effect of SiAgo2 transfection, western blotting was performed. Briefly, BMSCs were collected and lysed to obtain protein. The protein concentration was determined by a BCA protein assay (Thermo Fisher, USA). Twenty milligrams of total protein samples were separated on $4-12 \%$ Bis-Tris protein gels at $150 \mathrm{~V}$ for $40 \mathrm{~min}$, transferred to a polyvinylidene fluoride membrane, and blocked in 10\% western blotting buffer for $30 \mathrm{~min}$. The membrane was then stained with a primary anti-Ago2 antibody (Sigma-Aldrich, SAB4200085, St. Louis, USA) for $1 \mathrm{~h}$, washed with TBST 3 times for 5 min each, and stained for $1 \mathrm{~h}$ with secondary antibody before a final wash and detection with Femto ECL. ImageJ software (NIH, Bethesda, Maryland, USA) was used to analyze the densities of the protein bands.

\section{The expression levels of miRNA in transfected BMSCs}

To validate the effect of SiAgo2 transfection on miRNA levels, the expression of miR-21, miR-146A, and miR17-92 in transfected BMSCs was further assessed using RT-PCR. Briefly, complementary DNA (cDNA) was generated from $1 \mu \mathrm{g}$ of total RNA using an M-MLV Reverse Transcriptase (RT) Kit (Promega, USA) and miRNAspecific looped RT primers (Sangong, China) (Table 1). Real-time PCR was performed using an ABI PRISM ${ }^{\circ}$ 7500 Sequence Detection System (Applied Biosystems, USA) and SYBR Green Real-Time PCR Master Mix (Toyobo, Japan). Data were analyzed using ABI PRISM ${ }^{\circ}$ 7500 Sequence Detection System Software, Version 2.0.1 (Applied Biosystems, USA). The levels of miRNA in BMSCs were calculated in relation to levels of U6 RNA (internal control).

\section{Transmission electron microscopy (TEM)}

EXO pellets collected by ultracentrifugation were resuspended in PBS, loaded onto a copper grid, and dried for 20 min at $40^{\circ} \mathrm{C}$, after which the whole preparation was stained with $3 \%$ phosphotungstic acid for 5 min. Subsequently, the samples were gently blotted dry with filter paper for $20 \mathrm{~min}$ at room temperature and observed by TEM (Hitachi H600, Japan). Five random fields for each grid were used to determine the average diameter of the EXOs. This process was repeated ten times. 


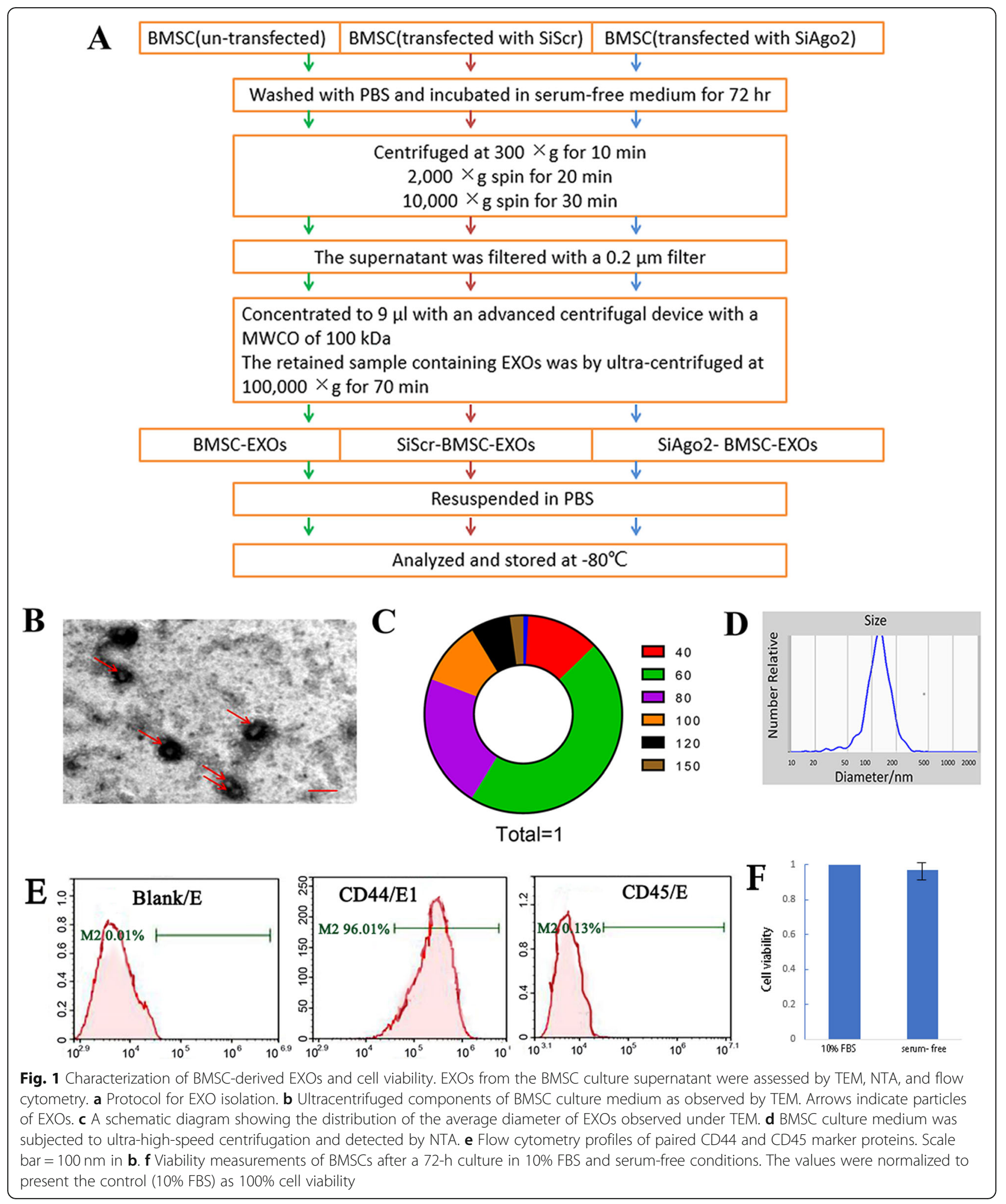


Table 1 Primers used for RT-PCR analysis of miRNA expression

\begin{tabular}{lll}
\hline miR-21 & Forward & TTGGCATTAAGCCCCAGCAA \\
& Reverse & AGCCATGCGATGTCACGACC \\
miR-146A & Forward & ATATGGAAGGGTCATGAGGC \\
& Reverse & AGAGATGGTGCAAA GACCC \\
miR-17-92 & Forward & AAGGCTTACATGTGTCCAATT \\
& Reverse & CACTTAGGGCAGTAGATGCT \\
U6 & Forward & GCTTCGGCAGCACATATACTAAAAT \\
& Reverse & CGCTTCACGAATTGCGTGTCAT \\
\hline
\end{tabular}

\section{Zetasizer experiments}

The size distribution and concentration of exosomes were measured with a Zeta View S/N 17-315 and the corresponding Zeta View 8.04.02 SP2 software (Particle Metrix, Meerbusch, Germany).

\section{Flow cytometry}

EXOs were analyzed using flow cytometry (ACEA Biosciences Inc., NovoCyte 1040 Cytometer, San Diego, California, USA). A CD45 FITC (1:1000 dilution; 11-0461-80, eBioscience, Thermo Fisher Scientific, USA) or a rat CD44 PE (1:400 dilution; 12-0444-80, eBioscience, Thermo Fisher Scientific, NY, USA) antibody was added for $1 \mathrm{~h}$ at $4{ }^{\circ} \mathrm{C}$ in the dark before flow cytometric analysis. Data were analyzed using Novo Express TM software (ACEA Biosciences Inc., San Diego, California, USA).

\section{EXO uptake experiments and immunofluorescence}

In vitro, BMSC-derived EXOs were labeled with a PKH67 Green Fluorescent Cell Linker Kit (Sigma-Aldrich, MINI67) according to the manufacturer's protocol, with minor modifications. Specifically, EXOs were suspended in $0.5 \mathrm{ml}$ of diluent $\mathrm{C}$, to which $2 \mu \mathrm{l}$ of PKH67 dye was added and incubated with the EXO solution for $5 \mathrm{~min}$. To bind excess dye, $8 \mathrm{ml}$ of complete culture medium (containing 15\% FBS) depleted of EXOs by ultracentrifugation was added. The labeled EXOs were ultracentrifuged at $100,000 \times g$ for $70 \mathrm{~min}$, after which the EXO pellets were washed with PBS and ultracentrifuged again. The EXO pellets were diluted in $100 \mu \mathrm{l}$ of PBS and used for uptake experiments. Then, $0.5 \mathrm{ml}$ of the EXO (approximately $5 \times$ $10^{6}$ particles) suspension was added to a $1.5 \mathrm{ml}$ of the DRG cell culture system (approximately $1 \times 10^{6}$ cells) obtained from 6 to 8 -week-old SD rats [30] and incubated for $48 \mathrm{~h}$. The cells were fixed in $4 \%$ paraformaldehyde for 20 min at RT, washed with PBS, stained with an anti- $\beta$ tubulin III (Millipore, Mab5564, USA) antibody at $4{ }^{\circ} \mathrm{C}$ overnight, washed 3 times with $0.1 \mathrm{M} \mathrm{PBS}$, and then incubated with donkey anti-mouse IgG conjugated to Alexa Fluor594 (Thermo Fisher Scientific, A-21203). Uptake of labeled EXOs by neurons/glial cells was visualized using confocal microscopy (Olympus FV1000, Tokyo, Japan). Z- stacks covering the entire cell volume were obtained, and three independent experiments were performed. Five visual fields were used to count labeled cells to calculate the mean transfection rate.

In vivo, SNC rats were administered $4 \mu \mathrm{l}$ of PKH67labeled EXOs $\left(0.9 \times 10^{10}\right.$ in PBS) via gastrocnemius muscle injection (in the proximal $2 / 10$ and $3 / 10$ of the calf length, where the intramuscular nerve endings of the gastrocnemius muscle are densely distributed) [31]. L4-L6 DRG samples were obtained at 3 time points (1, 5 , and 7 days after injection, with 4 rats for each time point). Half of these samples were sectioned into $30 \mu \mathrm{m}$ thick slices and stained with DAPI (Boster, USA) for 1 min at RT. Then, the sections were washed 3 times with 0.1 M PBS. The remaining DRGs were stored at $-80^{\circ} \mathrm{C}$ for qRT-PCR.

\section{Measurement of DRG neuron neurites}

To assess the effect of BMSC-derived EXOs on neuritic outgrowth, BMSC-derived EXOs, SiScr-BMSCs, SiAgo2BMSCs, SiScr-BMSC-EXOs, and SiAgo2-BMSC-EXOs were cultured with rat primary DRG neurons. Cultured neurons alone (PBS) were used as a negative control group. After $48 \mathrm{~h}$ of incubation, the number of processes and the neurite lengths of the neurons were recorded in five random visual fields.

\section{Experimental design for SNC injury and functional recovery}

After intraperitoneal anesthesia, the sciatic nerve of an SD rat was exposed by separating the gluteal muscles and squeezing the nerve $5 \mathrm{~mm}$ under the infrapiriform foramen for $5 \mathrm{~s}$ with forceps (Dumont No. 5) until the nerve became translucent. The forceps were then rotated $120^{\circ}$, and the squeezing was repeated twice. This process ensured that the sciatic nerve axons in the transected nerve epineurium remained intact.

SNC rats were administered $4 \mu \mathrm{l}$ of PBS, BMSCs, or EXOs via gastrocnemius muscle injection (in the proximal $2 / 10$ and $3 / 10$ of the calf length, where the intramuscular nerve endings of the gastrocnemius muscle are densely distributed) [31]. EXO-treated rats were redivided into 4 subgroups $(n=6)$. PBS, BMSCs, and EXOs were administered with a Hamilton microinjector (Shanghai Gaoge, China); this procedure was repeated 3 times over 15 days (0, 7, and 14 days after SNC) [27] (Fig. 4a, b). The sciatic nerve functional index (SFI) and latency of thermal pain (LTP) measurements were recorded at $0,7,14,21$, and 28 days after SNC, and L4-L6 DRGs were collected 28 days after SNC [27].

\section{Footprint analysis}

To investigate functional recovery, a footprint test was performed before SNC and at 7, 14, 21, and 28 days after 
SNC [3] (Fig. 4a). A homemade Plexiglass runway $1 \mathrm{~m}$ long, $15 \mathrm{~cm}$ wide, and $15 \mathrm{~cm}$ high was constructed. To prepare for the experiments, the runway was lined with pieces of clean white paper, and ink was brushed on both hind paws of each rat. Subsequently, the rat entered the runway from one side and exited from the other side, leaving experimental lateral foot (E) and normal foot $(\mathrm{N})$ footprints for measurement. Three footprint variables were assessed: print length (PL, the distance from the heel to the toe), toe spread (TS, the distance from the first to the fifth toe line), and intertoe distance (IT, the distance from the second to the fourth toe line). These variables were substituted into the Bain formula, as follows:

$\mathrm{SFI}=-38.3 \times(\mathrm{EPL}-\mathrm{NPL}) / \mathrm{NPL}+109.5 \times(\mathrm{ETS}-$ $\mathrm{NTS}) / \mathrm{NTS}+13.3 \times(\mathrm{EIT}-\mathrm{NIT}) / \mathrm{NIT}-8.8$, where SFI $=0$ is normal and SFI $=-100$ indicates complete neurodegeneration [4].

\section{Measurement of LTP}

To determine the hindlimb pain threshold, the paw withdrawal thermal latency (PWTL) test was performed before and 7, 14, 21, and 28 days after SNC (Fig. 4a). An RB-200 intelligent hot plate tester (Shanghai Yilian Medical Instrument Development Co., Ltd., China) was set to $55^{\circ} \mathrm{C}$ and preheated for $15 \mathrm{~min}$ until the constant temperature indicator light became bright. The rats were numbered and placed on the plate. The latency from the appearance of the light to brisk withdrawal of the hindlimb paw was measured. To avoid tissue damage, the time did not exceed $40 \mathrm{~s}$. Each measurement was repeated 3 times, with 15 min intervals between measurements.

\section{qRT-PCR}

mRNA was extracted from the L4-L6 DRGs of the rats using an animal total RNA extraction kit (Generay Biotech, GK3015, Shanghai, China) for analysis. Briefly, $1 \mu \mathrm{g}$ of total mRNA was reverse transcribed to cDNA using a HiScript II One Step RT-PCR Kit (Vazyme Biotech, P611-01, Nanjing, China). RT-PCR was performed using the CFX Connect Real-Time PCR System with ChamQ SYBR Color qPCR Master Mix (Vazyme Biotech, Q41102) and unique primers (Table 2). Seven samples from each group were assayed.

\section{Measurement of the number and diameter of regenerated nerve fibers}

The distal sciatic nerve trunk of the SNC site $(5 \mathrm{~mm})$ was obtained on the 28th day after SNC and sectioned into $10 \mu \mathrm{m}$ thick slices. After $20-30 \mathrm{~min}$ of staining with $1 \%$ toluidine blue, the slices were examined under a microscope (Olympus FV1000, Tokyo, Japan). Regenerated nerve fibers were counted in five random visual fields, and their diameters were analyzed using iP-win32
Table 2 Primers used for RT-PCR analysis of gene expression

\begin{tabular}{lll}
\hline Akt1 & Forward & GTGGCAAGATGTGTATGAG \\
& Reverse & CTGGCTGAGTAGGAGAAC \\
PMP22 & Forward & TCGCGGTGCTAGTGTTGC \\
& Reverse & GACAGGACGCTGAAGATGACA \\
NGFr & Forward & CTGGGCTGATGCTGAATGC \\
& Reverse & TATCCGCCACTGTACTGGGTA \\
S100b & Forward & GGGTGACAAGCACAAGCTGAA \\
& Reverse & AGCGTCTCCATCACTTGTCCA \\
VEGFA & Forward & GGCTCACTTCCAGAAACACG \\
& Reverse & GTGCTCTTGCAGAATCTAGTGG \\
HGF & Forward & ATTGCCCTATTCCCGTTGT \\
& Reverse & TTCAAACTAACCATCCACCCT \\
hGAPDH & Forward & CAATGACCCCTCATTGACC \\
& Reverse & GACAAGCTTCCCGTTCTCAG
\end{tabular}

medical image metrology software (Molecular Devices, CA, USA). The measured data are expressed as $\bar{X} \pm S$.

\section{Statistical analyses}

All statistical analyses were performed using SPSS 17.0 (IBM SPSS, Inc., Chicago, IL), and the data are presented as $\bar{X} \pm S$, with graphs constructed using GraphPad Prism (La Jolla, CA). SFI, LTP, and myelinated fiber count data were statistically analyzed by one-way ANOVA, and comparisons between groups were performed by the Bonferroni method. A $p$ value $<0.05$ indicated statistical significance.

\section{Results}

\section{Characterization of BMSC-derived EXOs}

EXO particles isolated from the culture supernatants of rat BMSCs had diameters that ranged between 30 and $120 \mathrm{~nm}$, as shown by TEM (Fig. 1b, c). However, particles with a size of 40 to $120 \mathrm{~nm}$ accounted for the largest proportion (Fig. 1c). The EXOs were physically homogeneous, with a diameter distribution that peaked at 118.3 $\mathrm{nm}$, as determined by nanoparticle tracking analysis (NTA) (Fig. 1d). The tetraspanin family of proteins including CD63, CD44, and CD9 are EXO markers [8, 29, 32]. CD44 expression, but not CD45 expression, was detected by flow cytometry (Fig. 1e). Overall, these results suggest that EXOs can be successfully extracted from the culture supernatant of rat BMSCs for further application.

\section{BMSC-derived EXOs can be transferred into neurons in vitro and in vivo and glial cells in vivo}

To determine whether EXOs can be taken up by neurons and glial cells, BMSC-derived EXOs were labeled with PKH67 and subsequently added to a DRG culture system. After a 48-h incubation with labeled EXOs, 
numerous cells acquired a positive PKH67 signal (Fig. 2a-e), which indicates that BMSC-derived EXOs and their cargo can enter neurons and glial cells in vitro. PKH67 labeling was observed in neuronal nuclei by confocal laser scanning microscopy (Fig. 2e).

L4-L6 DRG sections were observed and found to exhibit PKH67 labeling by fluorescence microscopy. One day after the injection of EXOs, neurons and glia on both sides of the DRG exhibited PKH67 labeling (green). Five days after EXO injection, the number of neurons labeled with PKH67 was significantly higher in the ipsilateral (right side) DRG than in the contralateral DRG $(p<0.01)$ (Fig. $2 \mathrm{~g}-\mathrm{i})$. Compared with the contralateral DRG neurons, more ipsilateral DRG neurons were labeled with PKH67 (Fig. 2g, h), and almost no labeled glial cells were found on either side. These results suggest that EXOs undergo retrograde transport into DRG neurons and glial cells by passing through blood and nerve fibers. Therefore, BMSCs can be taken up by neurons and glial cells in vitro and in vivo.

\section{BMSC-derived EXOs promote neuritogenesis of cultured primary DRG neurons through miRNA-dependent mechanisms}

To investigate whether the effect of EXOs on nerve growth is related to miRNA, we transfected BMSCs with an siRNA targeting Ago2 (SiAgo2) to reduce miRNA synthesis. SiAgo2-mediated Ago2 knockdown was confirmed by western blotting (Fig. 3a), and the expression of miR-21, miR-146A, and miR-17-92 in transfected BMSCs was decreased, as evidenced by RT-PCR (Fig. 3b). To quantify the effect of BMSC-derived EXOs on DRG neurons, we measured the number of processes and the neurite lengths of neurons (Fig. 3e). At $48 \mathrm{~h}$ after coculture, the mean number of neuronal processes in the EXO group was $6.66 \pm 1.32$, which was significantly higher than that in the PBS group $(3.06 \pm 1.43)$ $(p<0.001)$ (Fig. 3c, e). We detected neurite lengths of $92.6 \pm 20.4 \mu \mathrm{m}$ in the PBS group and $222.3 \pm 48.8 \mu \mathrm{m}$ in the EXO group, and this difference was statistically significant $(p<0.001)$ (Fig. 3d, e). Furthermore, we used this coculture system in which SiAgo2 was used to knock down Ago2 (SiAgo2-BMSC-EXO group) to observe the effect of EXOs secreted by BMSCs on the growth of primary cultured neurons (Fig. 3e). SiAgo2BMSCs served as a positive control, and the SiScrBMSC and SiScr-BMSC-EXO groups served as normal controls. After $48 \mathrm{~h}$ of culture, the mean neurite number $(2.44 \pm 0.35)$ and mean neurite length $(66.4 \pm 18.6 \mu \mathrm{m})$ in the SiAgo2-BMSC-EXO group were not significantly different from those in the SiAgo2-BMSC group $(2.17 \pm$ 0.54 and $75.4 \pm 11.8 \mu \mathrm{m})(p>0.05)$. However, the two
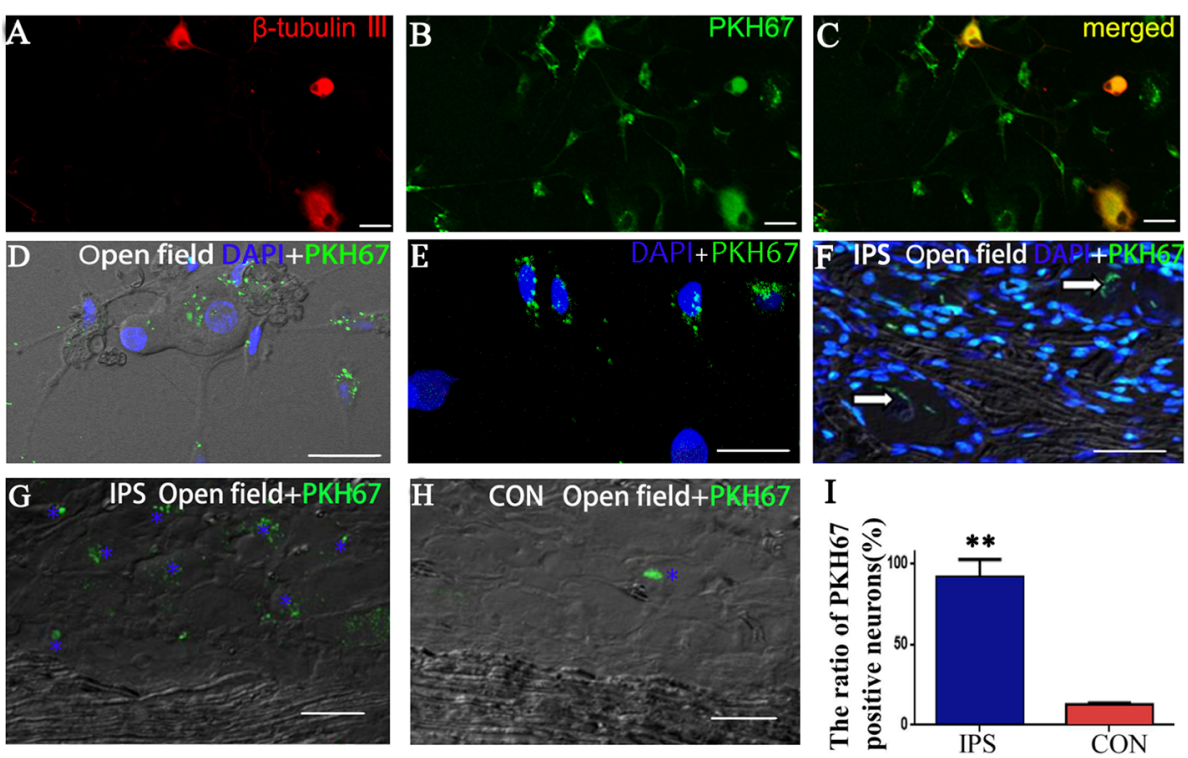

Fig. 2 EXOs were ingested by cultured DRG neurons and glial cells in vitro and in vivo. a-d EXOs were ingested by cultured DRG neurons and glial cells after coincubation of DRG neurons (red) and EXOs labeled with PKH67 (green). a $\beta$-Tubulin III-labeled neurons. b The PKH67 marker is shown in cultured cells. $\mathbf{c}$ a and $\mathbf{b}$ merged. $\mathbf{d}$ By laser confocal microscopy, the open field shows that the cultured DRG cells were labeled with PKH67. e In cultured DRG cells, some of the EXOs labeled with PKH67 can be seen in the nucleus. $\mathbf{f}-\mathbf{h}$ Five days after EXOs were injected into the gastrocnemius muscle, they entered DRG neuronal cell bodies and glial cells. $\mathbf{f}$ PKH67-labeled cells were visible in the ipsilateral DRG, and the PKH67 marker was present in the neuron cell body in an open field (arrow). $\mathbf{g}, \mathbf{h}$ An open field under laser confocal microscopy showed the ipsilateral (g) and contralateral (h) DRG (without DAPI). Stars indicate PKF67-positive neurons in the DRG. i Five days after injection, the bilateral DRG PKH67-positive cell ratio (\%) was statistically analyzed, and double asterisks indicate significant differences between the two sides $(p<0.01)$. Scale bar $=40 \mu \mathrm{m}$ in $\mathbf{a}, \mathbf{b}$, and $\mathbf{c}$ and $10 \mu \mathrm{m}$ in $\mathbf{d}-\mathbf{h}$. Images at $\times 40$ magnification (objective) and aperture $=225 \mu \mathrm{m}$ in $\mathbf{d}-\mathbf{h}$ 


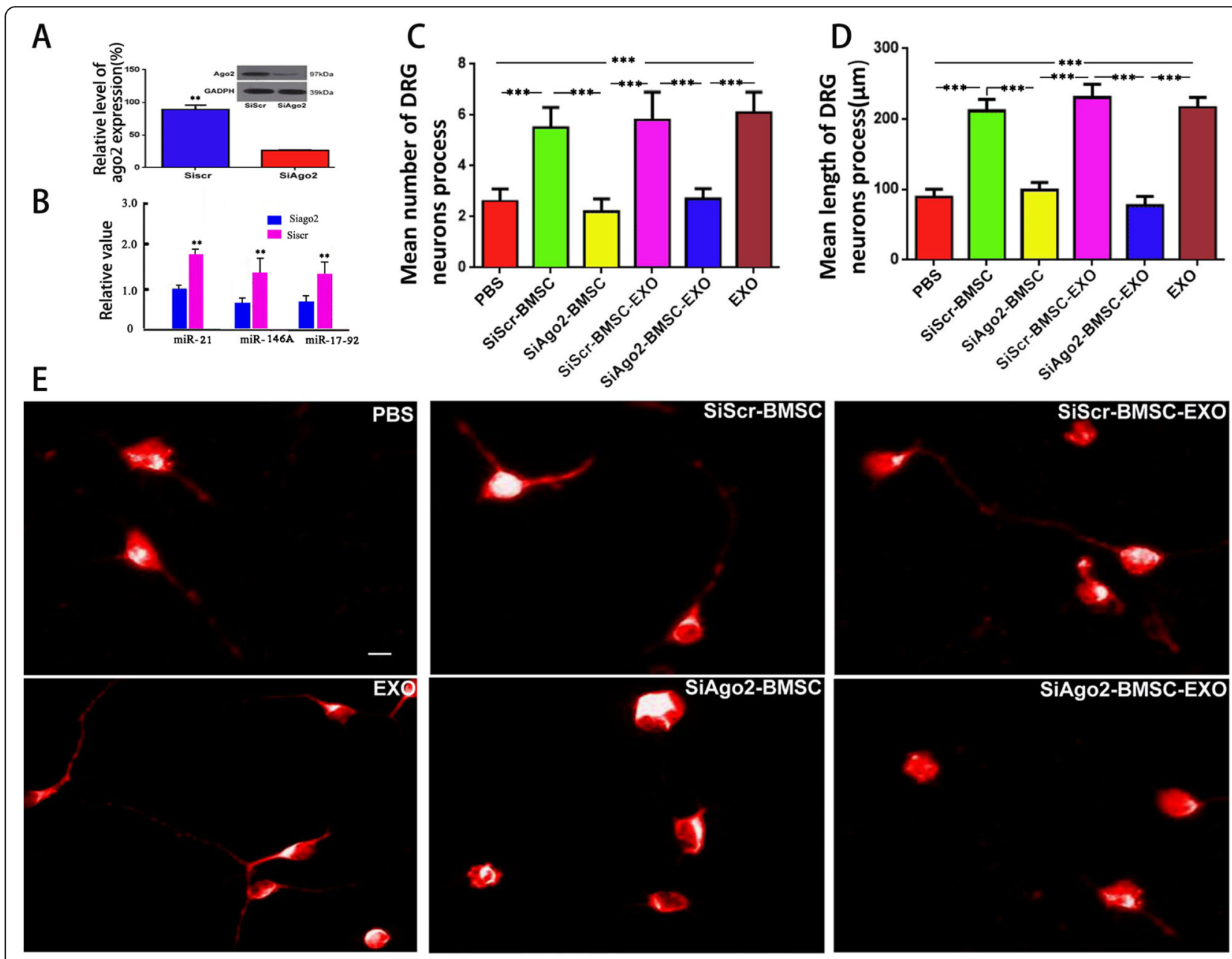

Fig. 3 The effect of EXO miRNAs on nerve growth in vitro. Western blotting for Ago2 knockdown. $\mathbf{b}$ The relative values of miR-21, miR-146A, and miR17-92 expression in transfected BMSCs. c Number of DRG neurons bearing neurites. $\mathbf{d}$ The mean length of neurites. Asterisks indicate that the difference between the two groups was statistically significant. Three asterisks indicate $p<0.001$, and two asterisks indicate $p<0.01$. e Images show the morphologies of cultured DRG neurons in each group. SiAgo2, siRNA against Argonaute-2; SiScr, scrambled siRNA control. Scale bar $=10 \mu \mathrm{m}$ in $\mathbf{e}$

average values in both groups were lower than those in the two normal control groups $(5.78 \pm 1.36,231 \pm 17.5 \mu \mathrm{m}$; $5.94 \pm 1.66,247 \pm 21.87 \mu \mathrm{m})$, and the differences were statistically significant $(p<0.001)$ (Fig. 3c-e). These results confirm that BMSCs and their EXOs are less effective in promoting neurite outgrowth in the absence of Ago2.

\section{BMSC-derived EXOs promote the regeneration and}

functional recovery of injured peripheral nerves

\section{Measurement of the number and diameter of regenerating} myelinated nerve fibers

Nerve fibers distal to the injured site were harvested on day 28 after SNC. Toluidine blue staining was then performed on the slices. The average number of myelinated nerve fibers in the EXO-D3 group was $8100 \pm 660$, and significant differences were found in the EXO-D3 group compared with the BMSC group $(7300 \pm 460)(p<0.05)$ and PBS group $(2300 \pm 260)(p<0.001)$. The diameter of myelinated nerve fibers in the EXO-D3 group was $1.86 \pm 0.23 \mu \mathrm{m}$, and a significant difference was found in the EXO-D3 group compared with the BMSC group $(1.32 \pm 0.23 \mu \mathrm{m})$ $(p<0.05)$. Compared with that in the PBS group $(0.56 \pm$ $0.16 \mu \mathrm{m})$, the diameter of myelinated nerves in the EXOD3 group was significantly different $(p<0.001)$ (Fig. 4).

\section{Measurement of the LTP}

Compared with that measured 1 day after surgery, the LTP had gradually decreased in each group by the 14th day after SNC (Fig. 5a). By 28 days, the LTP in the EXOD3 group $(23.61 \pm 5.04 \mathrm{~s})$ was superior to the BMSC group $(26.8 \pm 7.34 \mathrm{~s}) \quad(p>0.05)$ and the PBS group $(58.6 \pm 11.12 \mathrm{~s})(p<0.001)$ (Fig. 5b).

\section{Gait measurement}

Furthermore, the gait of the rats was measured and analyzed, and the SFI was calculated. The SFI in each group gradually 
increased beginning on the 14th day after SNC (Fig. 6a). At 28 days after SNC, the SFI of the EXO-D3 group $(-0.34 \pm$ 0.07 ) was not different from that of the BMSC group ($0.28 \pm 0.05)$ but was better than that of the PBS group ($0.76 \pm 0.09)$, and this difference was statistically significant $(p<0.001)$ (Fig. 6b). These results confirm that BMSCderived EXOs accelerate regenerative fiber growth and the recovery of sensory and motor functions.
A dose-effect relationship was observed between EXOs and nerve regeneration

Measurement of the number and diameter of regenerated myelinated nerve fibers

As described above, 28 days after SNC, the distal nerve trunk of the injury site was removed, and toluidine blue staining was performed. The number and diameter of regenerated myelinated fibers in the EXO-D3 group

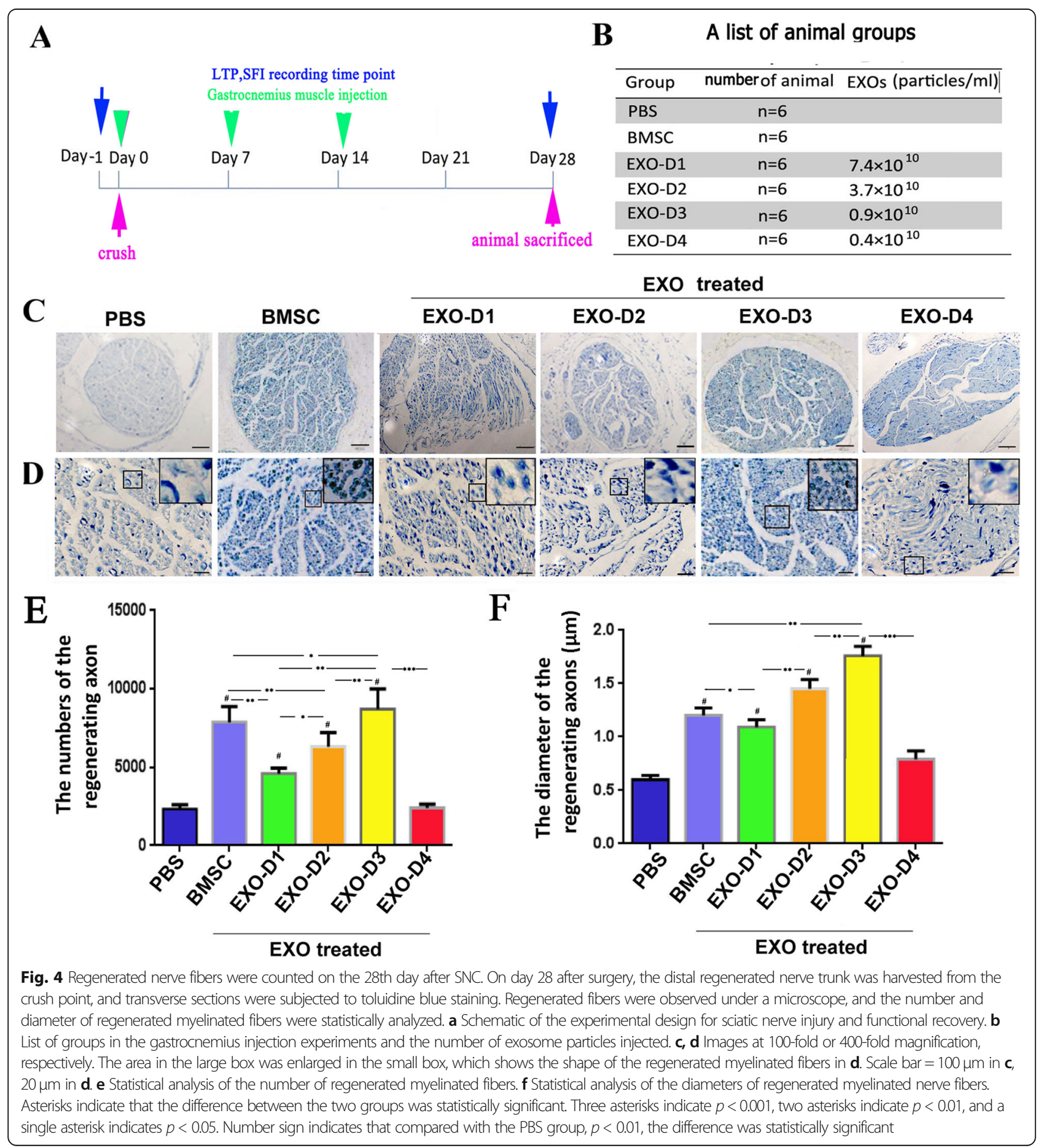



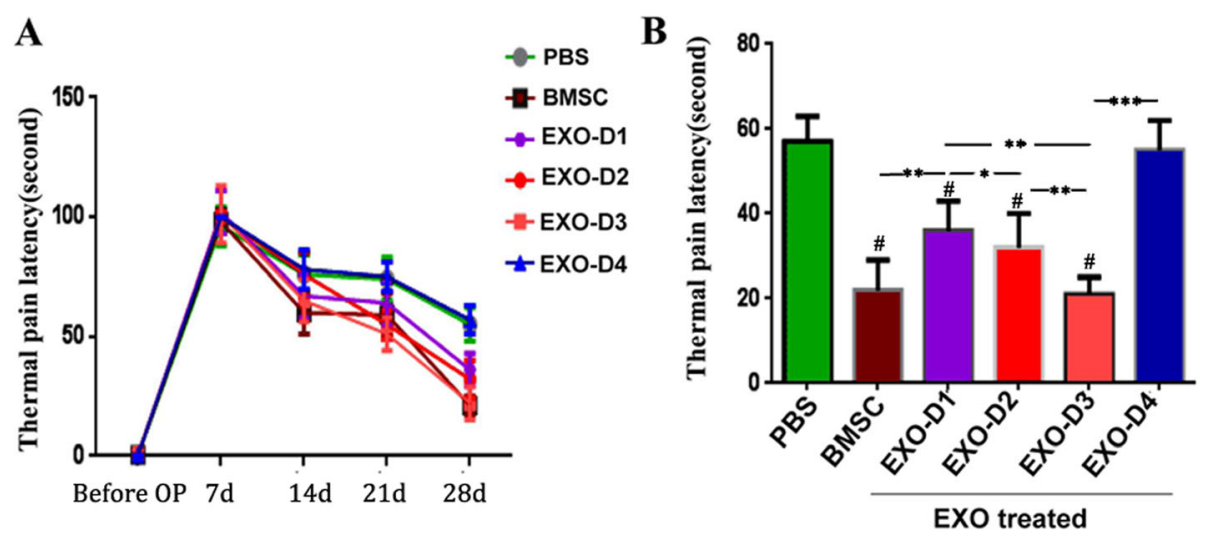

Fig. 5 Latency of thermal pain (LTP). Preoperative and postoperative LTP at each time point. b On day 28 after surgery, the LTP in each group was compared and analyzed. Asterisks indicate that the difference between the two groups was statistically significant. Three asterisks indicate $p<0.001$, two asterisks indicate $p<0.01$, and a single asterisk indicates $p<0.05$. Number sign indicates that compared with the PBS group, $p<0.01$, the difference was statistically significant

$(8100 \pm 660$ and $1.86 \pm 0.23 \mu \mathrm{m})$ were the highest of all the EXO-treated groups (Fig. 4c-e) and were significantly different from the values of the other dose groups $(p<0.01)$. These two values in the EXO-D2 group $(6200 \pm 420$ and $1.49 \pm 0.21 \mu \mathrm{m})$ were better than those in the EXO-D1 group $(4810 \pm 410$ and $1.24 \pm 0.17 \mu \mathrm{m}$ ), and those in the EXO-D1 group were better than those in the EXO-D4 group $(2110 \pm 215$ and $0.75 \pm 0.08 \mu \mathrm{m})$. According to pairwise comparisons, the differences were statistically significant $(p<0.01)$. However, no statistically significant difference was observed in these values between the EXOD4 and the PBS groups $(p>0.05)$ (Fig. $4 \mathrm{e}-\mathrm{f}$ ).

\section{Measurement of the LTP}

At 28 days after SNC, the LTP of the EXO-D3 group $(23.61 \pm 5.04)$ was the shortest among the groups treated with different EXO doses, and these differences were statistically significant $(p<0.01)$. The LTP value in the EXO-D2 group $(31.3 \pm 6.13 \mathrm{~s})$ was shorter than that in the EXO-D1 group $(37.7 \pm 6.00 \mathrm{~s})$, and that in the EXO-D1 group was shorter than that in the EXO-D4 group $(57.3 \pm 11.18 \mathrm{~s})$. The differences between the two groups were statistically significant $(p<0.01)$, but no statistically significant difference was found in these values between the EXO-D4 and PBS groups $(p>0.05)$ (Fig. 5b).
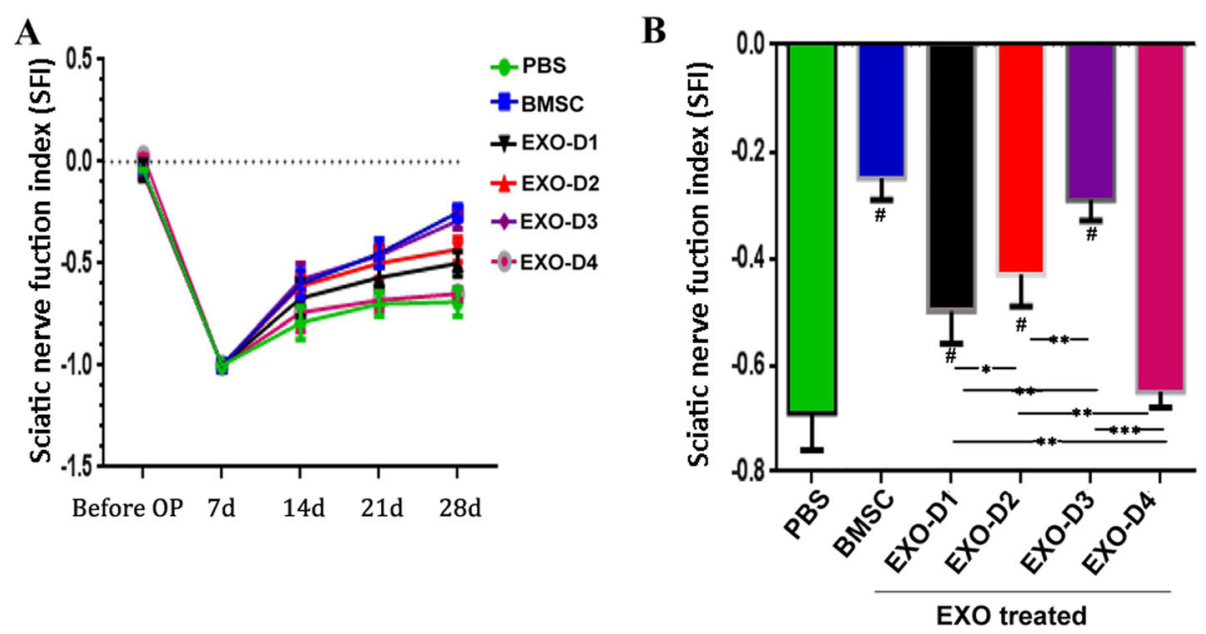

Fig. 6 Sciatic nerve motor functional index (SFI). a Preoperative and postoperative SFI at each time point. b At 28 days after SNC, the SFI in each group was compared and analyzed. Asterisks indicate that the difference between the two groups was statistically significant. Three asterisks indicate $p<0.001$, two asterisks indicate $p<0.01$, and a single asterisk indicates $p<0.05$. Number sign indicates that compared with the PBS group, $p<0.01$, the difference was statistically significant 


\section{Gait measurement}

At 28 days after SNC, the SFI value of the EXO-D3 group $(-0.34 \pm 0.07)$ was superior to the corresponding values of the other EXO-treated groups. The value of the EXO-D2 group was better than that of the EXO-D1 group, and that of the EXO-D1 group was better than that of the EXO-D4 group. The differences between the two groups were statistically significant. Of all the EXOtreated groups, the SFI of the EXO-D4 group was the lowest $(-0.73 \pm 0.08)$, and this value was not significantly different from that of the PBS group $(-0.72 \pm 0.09)$ $(p>0.05)$. These results confirm that BMSC-derived EXOs accelerate regenerative fiber growth and sensory and motor functional recovery as a result of a specific dose-effect relationship (Fig. 6b).

BMSC-derived EXOs upregulate PMP22, VEGFA, NGFr, and S100b gene expression in vivo

To preliminarily determine whether EXO-induced nerve regeneration is related to regulation of the expression of certain factors, L4-L6 DRGs were collected from rats 7 days after SNC. The expression of PMP22, VEGFA, NGFr, S100b, Akt1, and HGF was determined by qRTPCR. Compared with those in the PBS group, the relative expression levels of S100b, VEGFA, NGFr, and PMP22 in the EXO-D3 group were significantly higher $(p<0.01)$. Moreover, the relative expression of S100b and VEGFA in the EXO-D3 group was higher than that in the BMSC group, and the differences were statistically significant $(p<0.05)$ (Fig. 7).

\section{Discussion}

To the best of our knowledge, this study is the first to explore the effects of different doses of EXOs on sciatic nerve regeneration by injecting BMSC-derived EXOs into the gastrocnemius muscle. To that end, we utilized an SNC model of peripheral nerve injury, which is characterized by partial injury of motor neurons in the anterior horn of the spinal cord and sensory neurons in the DRG. Since a nerve suture is not needed in this model, the artificial effect of nerve regeneration is reduced [33]. In this SNC model, we demonstrated the significant neuroprotective and axogenic effects of BMSC-derived EXOs, as well as their capacity to preserve sciatic nerve function. We also used an in vivo experiment to reveal that EXOs promote nerve regeneration and noted that the appropriate dose may increase the effect of EXOs on nerve regeneration. In addition, we preliminarily demonstrated that EXOs may promote nerve regeneration in an miRNA-dependent manner and that the upregulation of PMP22, NGFr, VEGFA, and S100b expression may play an important role in this process.

Many factors, including the regulation of gene expression in neurons, the expression of neurotrophic factors, the role of inflammatory factors at injury sites, and the activation of glial cells, affect peripheral regeneration [26]. Although it has been reported that BMSCs are not tumorigenic and have neuroprotective and axonotropic effects, the clinical application of BMSCs is limited because of the unpredictability of their long-term effects $[8,9]$. Recently, EXOs released by nearly all cell types have been shown to improve the nerve regeneration process [34]. Many studies have shown that exosomes are rich in miRNAs, which can regulate various physiological cellular processes by targeting transcription factors and genes related to various cellular signaling pathways and processes, such as angiogenesis, cell transportation, apoptosis, and protein hydrolysis [35, 36]. Substantial evidence indicates that EXO miRNAs are critical vascular regeneration agents in the nervous

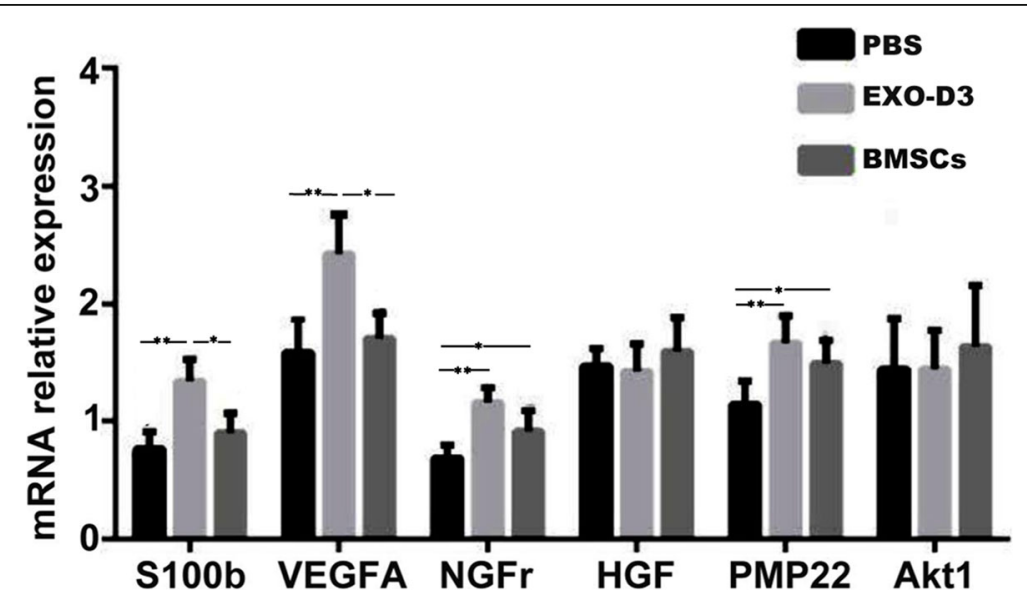

Fig. 7 Seven days after surgery, the expression levels of genes related to DRG tissue regeneration were detected by qRT-PCR. On day 7 after surgery, the expression of regeneration-related factors in each group was compared and analyzed. Asterisks indicate that the difference in gene expression between the two groups was statistically significant: single asterisk, $p<0.05$, and double asterisks, $p<0.01$ 
system [37]. EXOs are also thought to play an important role in regulating nerve regeneration by transmitting miRNAs from Schwann cells, macrophages, and BMSCs [38]. By simple centrifugation [34], EXOs can be isolated relatively easily and can serve as a cell-free therapy that combines the benefits of BMSC-mediated paracrine repair without the risks [39]. EXOs can also be easily stored and do not proliferate, which means that it is easy to apply EXOs at specific doses [39, 40]. Due to their small size, EXOs can migrate into the DRG and lesion sites from the blood or nerve endings [41]. The phospholipid bilayer around EXO inclusion bodies protects them and makes them immune-inert, which is very important for therapeutic delivery [40].

Some studies have shown that EXOs are vesicles with a diameter of $40-120 \mathrm{~nm}$ [42], while other studies have reported the diameter of these vesicles to be $40-100 \mathrm{~nm}$ [43]. At present, EV isolation and purification methods cannot distinguish between different types of EVs, especially between EXOs and microbubbles less than $200 \mathrm{~nm}$ in diameter, or determine their cellular origins, especially in vitro. In this study, the reported EXO markers CD44 and CD63 [44, 45] were detected in these membrane vesicles, further confirming the successful isolation of BMSC-derived EXOs. The mean diameter of the EXOs detected by TEM was different from that detected by NTA. The median diameter detected by NTA (118.3 $\mathrm{nm}$ ) was slightly larger than that detected by TEM. One of the reasons for this discrepancy is that different statistical methods were used, but it is possible that EXOs separated by ultracentrifugation contain microbubbles and broken cell components. Differential centrifugation is considered the best method to isolate EXOs from cultured cells. The first step of this process is low-speed centrifugation $(300 \times g$ for $10 \mathrm{~min}, 2000 \times g$ for $10 \mathrm{~min}$, $4{ }^{\circ} \mathrm{C}$ ) to remove cells and fragments, and the second step is ultracentrifugation $\left(100,000 \times g\right.$ for $\left.24 \mathrm{~h}, 4^{\circ} \mathrm{C}\right)$ to collect EXOs [29]. Note that ultrafiltration between the two steps can be used to concentrate the EXOs and simultaneously filter out impurities and EVs larger than 220 $\mathrm{nm}$ in diameter. However, it remains impossible to remove microbubbles smaller than $220 \mathrm{~nm}$ in diameter.

EVs containing cell membranes, such as EXOs, can bind to target cells through a series of surface adhesion proteins and carrier ligands (tetramers, integrins, CD11b and $\mathrm{CD} 18$ receptors) and can be internalized or transfer their payload to target cells [29, 32]. At present, EXO can be labeled in many ways. Among these labels are lipophilic fluorescent labels that include PKH26 and PKH67 [46]. Here, we labeled EXOs with PKH67. Using incubation with cultured DRG cells and gastrocnemius muscle injection, we observed PKH67 labeling in the neuronal body and nucleus. We confirmed that BMSCderived EXOs were internalized into DRG neurons and glial cells in vivo. These findings suggest that EXOs and their cargo can be transferred between these cells. Notably, we clearly observed the distribution of fluorescent markers in living neurons using open-field and fluorescence observations. This method is simpler and faster than fluorescence double-labeling.

EXOs contain both proteins and small RNAs, both of which can regulate the therapeutic effect of EXOs [47]. Ago2 knockout can reduce miRNA number and regulate miRNA function [31, 48, 49]. Mead et al. reported that RGC neuroprotection and RGC functional preservation by BMSC EXOs were significantly inhibited after Ago2 knockdown [27]. Here, we demonstrated that EXOs derived from BMSCs in which Ago2 had been knocked down attenuated the growth of neuronal processes in vitro. This protein analysis shows that BMSC EXOs carry no candidate neurotrophic factors (NTFs) as cargo but carry other proteins that can participate in the regenerative process $[50,51]$. Our results suggest that miRNAs are involved in the ability of BMSC-derived EXOs to promote nerve regeneration. One of these candidate genes is miR-17-92, which is found in BMSCderived EXOs [48]. miR-17-92 was found to target and downregulate the expression of phosphatase and tensin homolog (PTEN) [48], an important inhibitor of axonal growth and survival [52]. miR-21 has been shown to regulate the expression of PTEN [53]. miR-146A, which is expressed in the EXOs of BMSCs [54], targets epidermal growth factor receptor (EGFR) mRNA [55] and inhibits axon regeneration, while its receptor blockade promotes axon regeneration [56, 57]. BMSC-derived EXOs activate the Akt pathway [58], which is a complete pathway for neuron survival and regeneration [10].

Primary DRG culture is an accepted in vitro model in which to study peripheral nerve regeneration [59]. Neurite formation and elongation following interactions with other types of cells and/or under special culture conditions can be examined in this model [30]. Xin et al. showed that EXOs may regulate axon growth in the central nervous system $[60,61]$. Our results show that the outgrowth of DRG neurons was improved after treatment with BMSC-derived EXOs for $24 \mathrm{~h}$. EXOs tend to enhance axon growth and increase axon length, which is particularly important for the regeneration of peripheral nerves because the time frame for successful nerve regeneration is limited [26].

To a large extent, the lack of standardized methods for the separation, quantification, and characterization of EXOs hinders the study of EXOs. TEM is often used for the identification and morphological examination of EXOs in the early stages of EXO research and has been demonstrated to be feasible. Direct visualization by TEM is applied in the laboratory, but this method is expensive. Due to their small size, EXOs are not suitable for 
optical microscopy or flow cytometry [62]. When EXOs are detected by flow cytometry, a group of exosomes is usually regarded as a single EXO rather than a group of single EXOs; in other words, multiple EXOs are irradiated by the laser at the same time and often give a single signal, which leads to the underestimation of EXO concentrations [63]. NTA is a light-scattering technique designed to characterize nanoparticles [64]. In EXOs suspended in body fluid, a direct correlation is observed between the Brownian motion rate and EXO diameter. Using this established correlation, NTA can generate frequency and size distribution data by tracking the Brownian motion of EXOs in suspension, thus allowing visualization of EXOs [64]. When combined with temperature and viscosity data, NTA can estimate the size of EXOs relatively accurately with the StokesEinstein equation [64]. In recent years, NTA has become one of the most popular technologies used to directly count EXOs. NTA can also eliminate the cumbersome procedures involved in sample introduction, thereby reducing the possibility of contamination and more accurately estimating the EXO population count to protect the integrity of the sample and to reduce the time required to process each sample $[65,66]$. The disadvantage of conventional NTA is that this technique can simultaneously measure the volume and concentration of EXOs but cannot correctly distinguish between EXO phenotypes in multidispersed samples [66]. In this study, we used microfluidic methods to measure the concentration of EXOs, but the values after repeated measurements were quite different (data not shown). After NTA measurement, the repeatability was enhanced, and the concentration was somewhat higher than that measured using microfluidic methods. Actually, this concentration may reflect the inclusion of microvesicles. We determined the number of EXOs to be injected into the gastrocnemius muscle according to the concentration of EVs measured by NTA.

In this study, a classical rat SNC model was used. Crush injury is classified as a Sunderland III degree injury [33]. Nerve trunk continuity depends on a relatively complete epineurium, and when the nerve bundle is broken, axons, the nerve intima, and the perineurium are damaged. Continuous crush injury causes less damage than discontinuous crush injury, and recovery from uninterrupted crush injury is faster, which shortens the observation period, and is not affected by repair methods. Thus, the effect of interference from the surgical repair on the functional recovery results is eliminated, and the reliability and comparability of the experiment are ensured [33].

At present, intraperitoneal injection, intravenous injection, and local application are the main methods by which EXOs are applied in vivo [67-69]. Muscle injection is primarily used for the treatment and study of skeletal muscle atrophy [70]. However, few reports have been published on gastrocnemius muscle injection of EXOs for sciatic nerve regeneration. In another study, we injected EXOs into the gastrocnemius muscle to detect markers in DRG cells, and we detected the markers in two peaks between $24 \mathrm{~h}$ and 5 days after injection, which indicated that EXOs reach neurons not only quickly through blood transport but also slowly through retrograde transport via nerve fibers; this increases the duration of the effect of EXOs on neurons and the activity of the EXOs [28].

Recent studies have shown that EVs are involved in multiple pathological processes, such as insulin resistance, lipid toxicity, dyslipidemia, endocrine disorders, a hypercoagulable state, and chronic inflammation [71]. In this study, although the lowest dose (EXO-D4, 0.4 $\times$ $10^{10}$ ) was not able to lead to a significant difference from the PBS group, all the other doses of EXOs promoted nerve regeneration with respect to the control group. EXOs showed a somewhat unprogressive dose effect in the EXO-D1, EXO-D2, and EXO-D3 groups, and the highest dose $\left(\mathrm{EXO}-\mathrm{D} 1,7.4 \times 10^{10}\right)$ led to the lowest promoting effect compared with the PBS group. Regarding both the number and diameter of regenerating axons, EXO-D3 promoted an approximately 3 -fold maximum increase, while EXO-D1 induced an approximate 2-fold increase (versus the PBS control).

These results reveal that EXOs show a preference for nerve regeneration but that the relationship is not "the higher dose the better". Our findings were partly consistent with those of previous studies, which found that microvesicles inhibited neuritogenesis in cultured cortical neurons [72]. Negative neurogenic effects were reported in RGC cultures treated with high doses of EVs and were attributed to microbubbles. The filtration and removal of microbubbles from samples negated this dose-dependent effect [27]. Actually, it is almost impossible to remove all microvesicles by ultrafiltration because microvesicles are between 50 and $210 \mathrm{~nm}$ in diameter, and thus, some microvesicles are similar in diameter to EXOs and are difficult to remove. In addition, we cannot exclude small cellular debris, especially nuclear debris, from EXOs obtained by ultrafiltration. The presence of these microvesicles, proteins carried by nuclear debris and various RNAs, which may affect EXO function, is basically unknown [73]. These may be the reasons why EXO-D1 and EXO-D2 are much less effective than EXO-D3. In addition to the above reasons, we believe it is also possible that EXOs themselves carry a variety of active substances, such as proteins, lipids, miRNAs, dsRNAs, and cytokines. Why is EXO-D4 similar to the PBS control? One potential reason is that those active substances in EXO-D4 do not reach an effective concentration, and thus, they cannot promote nerve regeneration. Determining whether the 
effect of EXOs is difficult to control when EXOs are applied in large quantities is worth further assessment. Therefore, it is necessary to evaluate the safety of EXOs before clinical trials.

Toluidine blue staining of transverse nerve trunk sections remains the classic method by which the diameter of regenerated and myelinated fibers is measured [74]. In this study, toluidine blue staining of cross sections of regenerated fibers was used to measure the diameter of regenerated and myelinated fibers. Our results showed that 28 days after $\mathrm{SNC}$, the number and diameter of regenerated myelinated fibers in the BMSC group and all EXO-treated groups were higher than the corresponding values in the PBS group. Interestingly, the number and diameter of regenerated fibers in the EXO-D3 group were higher than those in the other EXO-treated groups and the BMSC group. Rats in the EXO-D4 group had the fewest regenerated fibers and the smallest regenerated fiber diameter among all the EXO-treated groups. These results suggest that BMSC-derived EXOs have at least the same ability as BMSCs to promote peripheral nerve regeneration and myelin formation and that the appropriate EXO dose is crucial.

LTP is a method used to measure pain or pain response. The tail-flick and hot plate methods are commonly used to measure the LTP in animal experiments. The use of the former method is limited in animals and greatly influences the test results [75]. When radiation heat is used as a pain stimulus instead of excitation of nonpain receptors, such as skin tactile sensors and pressure sensors, the excitation stimulus of polyphasic nociceptors is simpler. During the test, the animals are relatively free to move to avoid the release of endogenous analgesic substances caused by binding and fixation [76]. This method can be used to compare the pain response of the hind limbs in the same animal, reduce individual differences between animals, and eliminate interference from human factors via the use of automatic timing, which improves the reliability and accuracy of the test results. In this study, we observed that the LTP responses in the EXO-D3 and BMSC groups were significantly shorter than those in the PBS group and showed the most extensive effect. Almost no difference was observed in LTP between the EXO-D4 group and the PBS group, but the effect in the EXO-D1 and EXOD2 groups was not as strong as that in the EXO-D3 group. These results also suggest that BMSC-derived EXOs and BMSCs promote the recovery of sensory nerve function but that selection of an appropriate dose is important.

Walking track analysis is a comprehensive test that is widely used to evaluate motor functional recovery after traumatic peripheral nerve regeneration in rats [77]. Compared with the control treatment, a specific dose of
BMSC-derived EXOs improved the motor function and speed of sciatic nerve recovery over a certain period of time; this effect was similar to that observed after the direct application of BMSCs. However, the effect of BMSC-derived EXOs at the lowest dose examined (EXO-D4 group) was not as pronounced as that in the PBS group, and the application of too many EXOs (EXO-D1 and EXO-D2 groups) did not improve motor function as effectively as a suitable dose of EXOs (EXOD3 group). Combined with the LTP results, these findings show that BMSC-derived EXOs promote both sensory and motor nerve functional recovery.

Nerve regeneration may be related to myelin formation, glial cell activation, and angiogenesis, and studies have shown that BMSCs can synthesize various growth factors, including NGF, GDNF, NT-3, VEGFA, PMP22, HGF, and CNF [78-81]. These protein factors play an important role in peripheral nerve regeneration. Upregulation of PMP22 expression indicates that PMP22 can promote myelin formation [79]. The $\mathrm{S} 100$ protein, which consists of two polypeptides, S100a and S100b, is specific to peripheral nerves and is expressed at a relatively high concentration [81]. HGF plays a role in the development and maintenance of morphology in the brain and peripheral nervous system [82]. NGF plays a clear role in promoting peripheral nerve regeneration and binds to two kinds of transmembrane receptors [81]. Akt is a serine (Ser)/threonine (Thr) protein kinase that is also known as protein kinase B (PKB). At present, three subtypes of Akt have been found in mammals: Akt1, Akt2, and Akt3 [80]. Upregulation of VEGFA expression can accelerate angiogenesis and promote the recovery of nerve function. VEGFA is the most important growth factor in many cell types [83]. Our experiments showed that EXOs and BMSCs could upregulate the expression of PMP22, NGFr, VEGFA, and S100b in the DRG, which suggests that PMP22, NGFr, VEGFA, and S100b are four of the factors through which BMSCs and EXOs promote the recovery of neurological function. EXOs themselves contain not only genetic material but also a variety of proteins. Most cells, including glial cells, contain cytoskeletal proteins such as actin and tubulin in their EXOs, and these proteins play a key role in axon growth [81]. Studies have shown that active molecules such as HSP70 play an important role in neuronal metabolic support and protection [81]. Plasma galactose agglutinin-3 can affect phagocytosis of the myelin sheath. Plasma galactose agglutinin-3 has been shown to be upregulated in Schwann cells after nervous system injury and is also present in many types of microvesicles. Myelin proteins such as MAG and PLP can also be isolated from Schwann cell EXOs [84]. Studies have confirmed that AMPA, a protein found in neuronal EXOs, can be transferred between neurons $[85,86]$. 
EXOs can pass through natural barriers, such as the blood-brain barrier and blood-nerve barrier. These results show that BMSC-derived EXOs can also promote peripheral nerve regeneration by upregulating the expression of some factors related to peripheral nerve injury, which further enriches our understanding of the regulatory function of EXOs. Therefore, we believe that BMSC-derived EXOs have the potential to replace BMSCs for the repair of peripheral nerve injury.

\section{Conclusions}

The evidence obtained in this study suggested that BMSC-derived EXOs promote peripheral nerve regeneration and that the mechanism may involve the miRNAmediated regulation of the expression of regenerationrelated genes, such as VEGFA and S100b.

Furthermore, we used in vivo experiments to demonstrate for the first time that there is no clear positive correlation between nerve regeneration and EXO dose. High doses of EXOs do not produce the most substantial effect. We believe it is necessary to use EXOs as clinical therapeutic agents or drug carriers, improve EXO purification technology, and evaluate the preclinical safety of EXOs. The toxicity and negative effects of EXOs also deserve substantially more attention.

\section{Abbreviations}

BMSC: Bone marrow stromal cell; EXOs: Exosomes; SNC: Sciatic nerve crush; SFI: Sciatic nerve functional index; LTP: Latency of thermal pain; DRG: Dorsal root ganglion; MSCs: Mesenchymal stem cells; EV: Extracellular vesicle; RGCs: Retinal ganglion cells; TEM: Transmission electron microscopy; NTA: Nanoparticle tracking analysis

\section{Acknowledgements}

We are grateful for professional English language editing.

\section{Authors' contributions}

Jiuhong Zhao, Yali Ding, and Rui He wrote the manuscript; Kui Huang, Lu Liu, Chaona Jiang, Zhuozhou Liu, Yuanlan Wang, Xiaokai Yan, Fuyang Cao, XueYing Huang, Yanan Peng, Rui Ren, Yuebin He, and Tianwei Cui performed the experiments and obtained the original data; Quanpeng Zhang, Xianfang Zhang, and Qibing Liu performed the data analysis; and Yunqing Li, Zhijian Ma, and Xinan Yi designed the study. All authors read and approved the manuscript.

\section{Funding}

This project was funded by the National Natural Science Foundation of China (81660217 and 81460196), the Hainan Key Research and Development Program of China (ZDYF2018153 and ZDYF2016110), and the Natural Science Foundation of Hainan Province (318QN243).

\section{Availability of data and materials}

The datasets used and/or analyzed during the current study are available from the corresponding author on reasonable request.

\section{Ethics approval and consent to participate}

Animal sacrifice and collection were performed according to the guidelines of the China Laboratory Animal Nursing and Use Regulations and with the approval of the Animal Ethics Committee of Hainan Medical University.

\section{Consent for publication}

Not applicable

\section{Competing interests}

The authors declare that they have no competing interests.

\section{Author details}

${ }^{1}$ Key Laboratory of Brain Science Research \& Transformation in Tropical Environment of Hainan Province, Hainan Medical University, Haikou, China. ${ }^{2}$ Department of Anatomy, Hainan Medical University, Haikou, China. ${ }^{3}$ School of Medicine, Tibet University, Lhasa, China. ${ }^{4}$ Northwest Institute of Plateau Biology, Chinese Academy of Sciences, Xining, China.

Received: 3 January 2020 Revised: 28 July 2020 Accepted: 3 August 2020 Published online: 18 August 2020

\section{References}

1. Zheng MX, Hua XY, Feng JT, Li T, Lu YC, Shen YD, Cao XH, Zhao NQ, Lyu JY, Xu JG, Gu YD, Xu WD. Trial of contralateral seventh cervical nerve transfer for spastic arm paralysis. N Engl J Med. 2018;378:22-34.

2. Taylor CA, Braza D, Rice JB, Dillingham T. The incidence of peripheral nerve injury in extremity trauma. Am J Phys Med Rehabil. 2008:87:381-5.

3. Zhao Z, Wang Y, Peng J, Ren ZW, Zhang L, Guo QY, Xu WJ, Lu SB. Improvement in nerve regeneration through a decellularized nerve graft by supplementation with bone marrow stromal cells in fibrin. Cell Transplant. 2014:23:97-110

4. Kaiser R, Ullas G, Havránek P, Homolková H, Miletín J, Tichá P, Sukop A. Current concepts in peripheral nerve injury repair. Acta Chir Plast. 2017;59: 85-91.

5. Mahar M, Cavalli V. Intrinsic mechanisms of neuronal axon regeneration. Nat Rev Neurosci. 2018;19:323-37.

6. Thakor D, Spigelman I, Tabata Y, Nishimura I. Subcutaneous peripheral injection of cationized gelatin/DNA polyplexes as a platform for non-viral gene transfer to sensory neurons. Mol Ther. 2007;15:2124-31.

7. D WA, A SA, Shadi L, D EGR. Neuromodulatory nerve regeneration: adipose tissue-derived stem cells and neurotrophic mediation in peripheral nerve regeneration. J Neurosci Res. 2013;91:1517-1524.

8. Jiamei L, Hua Z, Ying L, Qin L, Shan L, Ming F, Yanfeng X, Lan H, Chunmei M, Yihua A, Chunhua ZR, Renzhi W, Chuan Q. Human mesenchymal stem cell transplantation protects against cerebral ischemic injury and upregulates interleukin-10 expression in Macaca fascicularis. Brain Res. 2010; 1334:65-72.

9. Zheng W, Honmou O, Miyata K, Harada K, Suzuki J, Liu H, Houkin K, Hamada $\mathrm{H}$, Kocsis JD. Therapeutic benefits of human mesenchymal stem cells derived from bone marrow after global cerebral ischemia. Brain Res. 2010; 1310:8-16.

10. Martin B, Zubair A, Barbara L, Michael D, Ann L. Regeneration of axons in the visual system. Restor Neurol Neurosci. 2008:26:147-74.

11. Lin L, Lin H, Shi B, Zheng L, Xiaoming Z. Bone marrow mesenchymal stem cells (BMSCs) improved functional recovery of spinal cord injury partly by promoting axonal regeneration. Neurochem Int. 2018;115:80-4.

12. NaRi S, Lee S-H, JaeMan JKW, BongJu K, SoungMin K, Jeong J, Lee J-H. Lowfrequency pulsed electromagnetic field pretreated bone marrow-derived mesenchymal stem cells promote the regeneration of crush-injured rat mental nerve. Neural Regen Res. 2018;13(1):145-53.

13. Kemin Y, Hongze C, Feng Z, Shen Y, Yan Z, Feng C, Liang L, Xiaodong L. Cell-seeded porous silk fibroin scaffolds promotes axonal regeneration and myelination in spinal cord injury rats. Biochem Biophys Res Commun. 2019; 514(1):273-9.

14. Na ZL, Chuan WJ, Mudenda ZPL, Qiong WY, Ping GW, Xia ZS, Hui L, Hong $\mathrm{ZJ}$, Dong DR, Feng CD. A comparison of the use of adipose-derived and bone marrow-derived stem cells for peripheral nerve regeneration in vitro and in vivo. Stem Cell Res Ther. 2020;11(1):153.

15. Yu Z, Xu N, Naili Z, Yanlian X, Wang Z, Liang S, Dongmei Z, Fei H, Chuansen $Z$. Repair of peripheral nerve sensory impairments via the transplantation of bone marrow neural tissue-committed stem cell-derived sensory neurons. Cell Mol Neurobiol. 2019;39(3):341-53

16. Marzesco AM, Janich $P$, Wilsch-Brauninger M, Dubreuil $V$, Langenfeld $K$, Corbeil D, Huttner WB. Release of extracellular membrane particles carrying the stem cell marker prominin-1 (CD133) from neural progenitors and other epithelial cells. J Cell Sci. 2005;118:2849-58.

17. Sorrentino V, Nelson JK, Maspero E, Marques AR, Scheer L, Polo S, Zelcer N. The LXR-IDOL axis defines a clathrin-, caveolae-, and dynamin-independent 
endocytic route for LDLR internalization and lysosomal degradation. J Lipid Res. 2013;54:2174-84.

18. Nakamura Y, Miyaki S, Ishitobi H, Matsuyama S, Nakasa T, Kamei N, Akimoto T, Higashi Y, Ochi M. Mesenchymal-stem-cell-derived exosomes accelerate skeletal muscle regeneration. FEBS Lett. 2015;589:1257-65.

19. Lamichhane TN, Sokic S, Schardt JS, Raiker RS, Lin JW, Jay SM. Emerging roles for extracellular vesicles in tissue engineering and regenerative medicine. Tissue Eng Part B Rev. 2015;21:45-54.

20. Pan $B T$, Johnstone RM. Fate of the transferrin receptor during maturation of sheep reticulocytes in vitro: selective externalization of the receptor. Cell. 1983;33:967-78.

21. Birner P, Schindl M, Obermair A, Plank C, Breitenecker G, Oberhuber G. Overexpression of hypoxia-inducible factor 1a is a marker for an unfavorable prognosis in early-stage invasive cervical cancer. Cancer Res. 2000;60:4693-6.

22. Goh V, Halligan S, Daley F, Wellsted DM, Guenther T, Bartram Cl. Colorectal tumor vascularity: quantitative assessment with multidetector $\mathrm{CT}$ - do tumor perfusion measurements reflect angiogenesis? Radiology. 2008;249: 510-7.

23. Valadi H, Ekström K, Bossios A, Sjöstrand M, Lee JJ, Lötvall JO. Exosomemediated transfer of mRNAs and microRNAs is a novel mechanism of genetic exchange between cells. Nat Cell Biol. 2007;9:654-9.

24. Sanchez DNR, Bertanha M, Fernandes TD, de Lima Resende LA, Deffune $E$, Amorim RM. Effects of canine and murine mesenchymal stromal cell transplantation on peripheral nerve regeneration. Inte I Stem Cells. 2017;10: 83-92.

25. Marofi F, Vahedi G, Biglari A, Esmaeilzadeh A, Athari SS. Mesenchymal stromal/stem cells: a new era in the cell-based targeted gene therapy of cancer. Front Immunol. 2017;8:1770.

26. Bucan V, Vaslaitis D, Peck C-T, Strauß S, Vogt PM, Radtke C. Effect of exosomes from rat adipose-derived mesenchymal stem cells on neurite outgrowth and sciatic nerve regeneration after crush injury. Mol Neurobiol. 2019;56:1812-24.

27. Mead B, Tomarev S. Bone marrow-derived mesenchymal stem cells-derived exosomes promote survival of retinal ganglion cells through mirnadependent mechanisms. Stem Cells Transl Med. 2017:6:1273-85.

28. Ren R, Tian XH, Zhao JH, Zhang QP, Zhang XF, Ma ZJ, Peng YN, Liu QB, Zhang HY, Li YQ, He R, Zhao ZQ, Yi XN. Bone marrow mesenchymal stem cell-derived exosome uptake and retrograde transport can occur at peripheral nerve endings. Artifific Cells Nano Med Biotechnol. 2019:47:2918-29.

29. Thery C, Amigorena S, Raposo G, Clayton A. Isolation and characterization of exosomes from cell culture supernatants and biological fluids. Curr Protoc Cell Biol. 2006;Chapter 3:Unit 322.

30. Melli G, Höke A. Dorsal root ganglia sensory neuronal cultures: a tool for drug discovery for peripheral neuropathies. Expert Opin Drug Discovery. 2009:4:1035-45.

31. Im S, ark JH, Son SK, Shin JE, Cho SH, Park GY. Does botulinum toxin injection site determine outcome in post-stroke plantarflexion spasticity? Comparison study of two injection sites in the gastrocnemius muscle: a randomized double-blind controlled trial. Clin Rehabil. 2014;28:604-13.

32. Théry C, Ostrowski M, Segura E. Membrane vesicles as conveyors of immune responses. Nat Rev Immunol. 2009;9:581.

33. Becker CM, Gueuning CO, Graff GL. Sutures or fibrin glue for divided rat nerves: Schwann cell and muscle metabolism. Microsurgery. 1985;6:1-10.

34. Tkach $\mathrm{M}$, Kowal J, Théry $\mathrm{C}$. Why the need and how to approach the functional diversity of extracellular vesicles. Philos Transact Royal Soc B: Biol Sci. 2017;373. https://doi.org/10.1098/rstb.2016.0479.

35. Eirin A, Riester SM, Zhu X-Y, Tang H, Evans JM, O'Brien D, van Wijnen AJ, Lerman LO. MicroRNA and mRNA cargo of extracellular vesicles from porcine adipose tissue-derived mesenchymal stem cells. Gene. 2014;551:55-64.

36. Zhang B, Shen L, Shi H, Pan Z, Wu L, Yan Y, Zhang X, Mao F, Qian H, Xu W. Exosomes from human umbilical cord mesenchymal stem cells: identification, purification, and biological characteristics. Stem Cells Int. 2016; 2016:1929536

37. Zhang B, Wu X, Zhang X, Sun Y, Yan Y, Shi H, Zhu Y, Wu L, Pan Z, Zhu W. Human umbilical cord mesenchymal stem cell exosomes enhance angiogenesis through the Wnt $4 / \beta$-catenin pathway. Stem Cells Transl Med. 2015:4:513-22.

38. Pegtel $\mathrm{D}$, Peferoen $\mathrm{L}$, Amor S. Extracellular vesicles as modulators of cell-tocell communication in the healthy and diseased brain. Philos Transact Royal Soc B: Biol Sci. 2014;369:20130516.
39. Hessvik NP, Llorente A. Current knowledge on exosome biogenesis and release. Cell Mol Life Sci. 2018;75:193-208.

40. Bosse F. Extrinsic cellular and molecular mediators of peripheral axonal regeneration. Cell Tissue Res. 2012;349:5-14.

41. Sohni A, Verfaillie C. Mesenchymal stem cells migration homing and tracking. Stem Cells Int. 2013:2013:130763.

42. Zaborowski MP, Balaj L, Breakefield XO, Lai CP. Extracellular vesicles: composition, biological relevance, and methods of study. Bioscience. 2015;65:783-97.

43. Raposo G, Stoorvogel W. Extracellular vesicles: exosomes, microvesicles, and friends. J Cell Biol. 2013;200:373-83.

44. Berkelaar M, Clarke DB, Wang YC, Bray GM, Aguayo AJ. Axotomy results in delayed death and apoptosis of retinal ganglion cells in adult rats. J Neurosci. 1994;14:4368-74.

45. Mesentier-Louro LA, Zaverucha-do-Valle C, da Silva-Junior AJ, NascimentoDos-Santos G, Gubert F, de Figueiredo AB, Torres AL, Paredes BD, Teixeira C, Tovar-Moll F, Mendez-Otero R, Santiago MF. Distribution of mesenchymal stem cells and effects on neuronal survival and axon regeneration after optic nerve crush and cell therapy. PLoS One. 2014;9:e110722.

46. Sunkara V, Woo H-K, Cho Y-K. Emerging techniques in the isolation and characterization of extracellular vesicles and their roles in cancer diagnostics and prognostics. Analyst. 2016;141:371-81.

47. Katsuda T, Ochiya T. Molecular signatures of mesenchymal stem cell-derived extracellular vesicle-mediated tissue repair. Stem Cell Res Ther. 2015;6:212.

48. Guduric-Fuchs J, O'Connor A, Camp B, O'Neill CL, Medina RJ, Simpson DA. Selective extracellular vesicle-mediated export of an overlapping set of microRNAs from multiple cell types. BMC Genomics. 2012;13:357.

49. Ha M, Kim VN. Regulation of microRNA biogenesis. Nat Rev Mol Cell Biol. 2014;15:509-24

50. Kim HS, Choi DY, Yun SJ, Choi SM, Kang JW, Jung JW, Hwang D, Kim KP, Kim DW. Proteomic analysis of microvesicles derived from human mesenchymal stem cells. J Proteome Res. 2012;11:839-49.

51. Fraga JS, Silva NA, Lourenço AS, Gonçalves V, Neves NM, Reis RL, Rodrigues AJ, Manadas B, Sousa N, Salgado AJ. Unveiling the effects of the secretome of mesenchymal progenitors from the umbilical cord in different neuronal cell populations. Biochimie. 2013;95:2297-303.

52. Park KK, Liu K, Hu Y, Smith PD, Wang C, Cai B, Xu B, Connolly L, Kramvis I, Sahin M, He Z. Promoting axon regeneration in the adult CNS by modulation of the PTEN/mTOR pathway. Science. 2008:322:963-6.

53. Meng F, Henson R, Wehbe-Janek H, Ghoshal K, Jacob ST, Patel T. MicroRNA21 regulates expression of the PTEN tumor suppressor gene in human hepatocellular cancer. Gastroenterology. 2007;133:647-58.

54. Baglio SR, Rooijers K, Koppers-Lalic D, Verweij FJ, Lanzón MP, Zini N, Naaijkens B, Perut F, Niessen HW, Baldini N. Human bone marrow-and adipose-mesenchymal stem cells secrete exosomes enriched in distinctive miRNA and tRNA species. Stem Cell Res Ther. 2015;6:127.

55. Katakowski M, Buller B, Zheng X, Lu Y, Rogers T, Osobamiro O, Shu W, Jiang F, Chopp M. Exosomes from marrow stromal cells expressing miR-146b inhibit glioma growth. Cancer Lett. 2013;335:201-4.

56. Douglas MR, Morrison KC, Jacques SJ, Leadbeater WE, Gonzalez AM, Berry M, Logan A, Ahmed Z. Off-target effects of epidermal growth factor receptor antagonists mediate retinal ganglion cell disinhibited axon growth. Brain. 2009;132:3102-21.

57. Koprivica V, Cho K-S, Park JB, Yiu G, Atwal J, Gore B, Kim JA, Lin E, TessierLavigne $M$, Chen DF. EGFR activation mediates inhibition of axon regeneration by myelin and chondroitin sulfate proteoglycans. Science. 2005;310:106-10.

58. Gu H, Ji R, Zhang X, Wang M, Zhu W, Qian H, Chen Y, Jiang P, Xu W. Exosomes derived from human mesenchymal stem cells promote gastric cancer cell growth and migration via the activation of the Akt pathway. Mol Med Rep. 2016:14:3452-8.

59. Mehnert JM, Kisch T, Brandenburger M. Co-culture systems of human sweat gland derived stem cells and peripheral nerve cells: an in vitro approach for peripheral nerve regeneration. Cell Physiol Biochem. 2014;34:1027-37.

60. Midha R, Cisterna BA, Grochmal J, Shakhbazau A, Hendriks WT, Van Minnen J. Morphological evidence for a transport of ribosomes from Schwann cells to regenerating axons. Glia. 2011;59:1529-39.

61. Lai RC, Arslan F, Lee MM, Sze NSK, Choo A, Chen TS, Salto-Tellez M, Timmers L, Lee CN, El Oakley RM. Exosome secreted by MSC reduces myocardial ischemia/reperfusion injury. Stem Cell Res. 2010:4:214-22.

62. Van Der Pol E, Hoekstra A, Sturk A, Otto C, Van Leeuwen T, Nieuwland R. Optical and non-optical methods for detection and characterization of microparticles and exosomes. J Thromb Haemost. 2010;8:2596-607. 
63. Soo CY, Song Y, Zheng Y, Campbell EC, Riches AC, Gunn-Moore F, Powis SJ. Nanoparticle tracking analysis monitors microvesicle and exosome secretion from immune cells. Immunology. 2012;136:192-7.

64. Montes-Burgos I, Walczyk D, Hole P, Smith J, Lynch I, Dawson K Characterisation of nanoparticle size and state prior to nanotoxicological studies. J Nanopart Res. 2010;12:47-53.

65. Al C, Kiss A, Cren C, Vulliet E, Buleté A. Development of an analytical method for the targeted screening and multi-residue quantification of environmental contaminants in urine by liquid chromatography coupled to high resolution mass spectrometry for evaluation of human exposures. Talanta. 2016;146:694-706.

66. Van Niel G, Mallegol J, Bevilacqua C, Candalh C, Brugiere S, TomaskovicCrook E, Heath JK, Cerf-Bensussan N, Heyman M. Intestinal epithelial exosomes carry MHC class II/peptides able to inform the immune system in mice. Gut. 2003;52:1690-7.

67. Takahashi Y, Nishikawa M, Shinotsuka H, Matsui Y, Ohara S, Imai T, Takakura $Y$. Visualization and in vivo tracking of the exosomes of murine melanoma B16-BL6 cells in mice after intravenous injection. J Biotechnol. 2013;165:7784

68. Nisim P, Oshra B, Ronit S, Shmuel B, Ariel A, Tamar S, Uri A, Rachela P, Daniel O. Golden exosomes selectively target brain pathologies in neurodegenerative and neurodevelopmental disorders. Nano Lett. 2019;19: 3422-31.

69. Wang B, Zhang A, Wang H, Klein JD, Tan L, Wang Z-M, Du J, Naqvi N, Liu BC, Wang XH. miR-26a limits muscle wasting and cardiac fibrosis through exosome-mediated microRNA transfer in chronic kidney disease. Theranostics. 2019;9:1864.

70. Wang H, Wang B, Zhang A, Hassounah F, Seow Y, Wood M, Ma F, Klein JD, Price SR, Wang XH. Exosome-mediated miR-29 transfer reduces muscle atrophy and kidney fibrosis in mice. Mol Ther. 2019;27:571-83.

71. Lopez-Verrilli MA, Caviedes A, Cabrera A, Sandoval S, Wyneken U, Khoury M. Mesenchymal stem cell-derived exosomes from different sources selectively promote neuritic outgrowth. Neuroscience. 2016;320:129-39.

72. Akers JC, Gonda D, Kim R, Carter BS, Chen CC. Biogenesis of extracellular vesicles (EV): exosomes, microvesicles, retrovirus-like vesicles, and apoptotic bodies. J Neuro-Oncol. 2013;113:1-11.

73. Mira J-C. Quantitative studies of the regeneration of rat myelinated nerve fibres: variations in the number and size of regenerating fibres after repeated localized freezings. J Anat. 1979;129:77.

74. Porro CA, Carli G. Immobilization and restraint effects on pain reactions in animals. Pain. 1988;32:289-307.

75. Hargreaves K, Dubner R, Brown F, Flores C, Joris J. A new and sensitive method for measuring thermal nociception in cutaneous hyperalgesia. Pain. 1988:32:77-88.

76. Varejão AS, Meek MF, Ferreira AJ, Patrício JA, Cabrita AM. Functional evaluation of peripheral nerve regeneration in the rat: walking track analysis. J Neurosci Methods. 2001;108:1-9.

77. Tseng T-C, S-h H. Substrate-mediated nanoparticle/gene delivery to MSC spheroids and their applications in peripheral nerve regeneration. Biomaterials. 2014;35:2630-41.

78. Fisher AC, McCulloch DL, Borchert MS, Garcia-Filion P, Fink C, Eleuteri A Simpson DM. Comparison of human expert and computer-automated systems using magnitude-squared coherence (MSC) and bootstrap distribution statistics for the interpretation of pattern electroretinograms (PERGs) in infants with optic nerve hypoplasia (ONH). Doc Ophthalmol. 2015;131:25-34

79. Notterpek L, Snipes GJ, Shooter EM. Temporal expression pattern of peripheral myelin protein 22 during in vivo and in vitro myelination. Glia. 1999:25:358-69.

80. Shi T-JS, Huang P, Mulder J, Ceccatelli S, Hökfelt T. Expression of p-Akt in sensory neurons and spinal cord after peripheral nerve injury. Neurosignals. 2009;17:203-12.

81. Moore BW. A soluble protein characteristic of the nervous system. Biochem Biophys Res Commun. 1965;19:739-44.

82. Achim C, Katyal S, Wiley C, Shiratori M, Wang G, Oshika E, Petersen B, Li J-M, Michalopoulos G. Expression of HGF and cMet in the developing and adult brain. Dev Brain Res. 1997;102:299-303.

83. Isner JM, Pieczek A, Schainfeld R, Blair R, Haley L, Asahara T, Rosenfield K, Razvi S, Walsh K, Symes JF. Clinical evidence of angiogenesis after arterial gene transfer of phVEGF165 in patient with ischaemic limb. Lancet. 1996; 348:370-4.
84. Pesheva P, Kuklinski S, Schmitz B, Probstmeier R. Galectin-3 promotes neural cell adhesion and neurite growth. J Neurosci Res. 1998;54:639-54.

85. Lee YS, Jung WY, Heo H, Park MG, Oh S-H, Park B-G, Kim S. Exosomemediated ultra-effective direct conversion of human fibroblasts into neural progenitor-like cells. ACS Nano. 2018;12:2531-8.

86. Frühbeis C, Fröhlich D, Krämer-Albers E-M. Emerging roles of exosomes in neuron-glia communication. Front Physiol. 2012;3:119.

\section{Publisher's Note}

Springer Nature remains neutral with regard to jurisdictional claims in published maps and institutional affiliations.
Ready to submit your research? Choose BMC and benefit from:

- fast, convenient online submission

- thorough peer review by experienced researchers in your field

- rapid publication on acceptance

- support for research data, including large and complex data types

- gold Open Access which fosters wider collaboration and increased citations

- maximum visibility for your research: over $100 \mathrm{M}$ website views per year

At BMC, research is always in progress.

Learn more biomedcentral.com/submissions 